\section{Use of central venous catheters in children}

\author{
JULIJE MEŠTROVIĆ • TANJA KOVAČEVIĆ • IVANKA ERCEGOVIĆ • \\ BRANKA POLIĆ • LUKA STRIČEVIĆ • ANTE OMAZIĆ • VESNA ČAPKUN
}

\author{
JULIJE MEŠTROVIĆ $(\bowtie) \cdot$ \\ IVANKA ERCEGOVIĆ • BRANKA POLIĆ • \\ LUKA STRIČEVIĆ • ANTE OMAZIĆ \\ Pediatric Intensive Care Unit \\ Department of Pediatrics \\ Split University Hospital \\ Spinčićeva 1, 21000 Split, Croatia \\ Telephone ++ 385 (0)21556686 \\ Fax ++385 (0)21556590 \\ e-mail: julije.mestrovic@st.t-com.hr \\ TANJA KOVAČEVIĆ \\ Department of Pediatrics, \\ Split University Hospital, Croatia \\ VESNA ČAPKUN \\ Department for Nuclear medicine, \\ Split University Hospital, Croatia
}

\begin{abstract}
The objective of this study was to evaluate the use of central venous catheters (CVCS) in the Pediatric intensive care unit (PICU) of Split University Hospital (SUH). We reviewed the records of all children that had CVCs and were hospitalized between January 2002 and March 2006. Patients were evaluated with respect to their age, gender, catheter type, indication for CVC insertion, site and side of the body of CVC insertion. The duration of catheter use and eventual complications were also taken into consideration. A total of $352 \mathrm{CVCs}$ were inserted in 300 children. Patient age ranged from 0 to 18 years. The average catheter insertion time was 12.88 days. We noted 66 (18.8\%) CVC-related complications. Complications related to CVCs insertion were malposition of catheter (5.4\%) and pneumothorax (0.9\%). Occlusion of CVCs (4.3\%), catheter relatedbloodstream infections (CRBI) (4.0\%), dislodgment (3.7\%) and catheter damage (0.6\%) were complications associated with lenght of CVCs use. We conclude that central venous catheterization is a safe and efficient procedure with minimal complications in pediatric patients.
\end{abstract}

Key words: central venous catheter, indications, complications, children.

\section{INTRODUCTION}

Central venous catheters (CVCs) have now become indispensable in intensive care units (1-3). Insertion of CVC is amongst the most frequently performed invasive procedures $(2,3)$. In severely ill and long-stay patients, inserted CVCs enable relatively safe and painless application of parenteral nutrition, long-term antibiotics, chemotherapy, intravenous fluids, blood components and is also used for repetitive blood sampling (3-6). Furthermore, CVCs are used for invasive hemodynamic monitoring, hemodialysis, plasmapheresis and in case of shortage of a peripheral access.
CVCs intended for children are made of a variety of materials, including silicone, polyurethane, polyvinyl chloride and polyethylene (3).

Access to a vessel can be gained via percutaneous puncture or with use of open surgical techniniques. "Seldinger" percutaneous technique is the most frequently used. CVCs are inserted via the subclavian vein, internal and external jugular veins or umbilical vein in newborns. The tip of the catheter can be placed into the right atrium, superior or high inferior vena cava (7-14).

When inserting CVC, the operator should be very experienced and cautious, given that possible complications are numerous and some of them can be very serious $(2,3,12)$. The percentage of known catheter-related complications range from 0.7 to $26 \%(1,3,12-16)$.

The objective of this study was to determine the frequency of application, indications and complications of CVCs in the Pediatric Intensive Care Unit of the Split University Hospital . By analyzing the obtained results, our intention was to compare them with published data pertaining to this issue and to verify our methods and procedures.

\section{MATERIAL AND METHODS}

We retrospectively evaluated all patients identified as having CVCs from January 2002 to March 2006 in the PICU of the SUH.

The data on indications for CVC placement, character of illness of patients 
with CVCs, total number of inserted CVCs, the most frequent insertion place and side, the average and total number of days of CVCs use and the most frequent complications related to CVCs, were evaluated.

All CVCs were placed by a specialized team of pediatric intensivists and nurses skilled in intensive care procedures and were carried out at the bedside. The procedures were performed in aseptic conditions with continuous monitoring of patient's electrocardiogram, heart rate and oxygen saturation. An appropriate catheter was chosen on the basis of the size of the patient. Polyurethane catheters were most commonly used, except in case of umbilical insertion when a silicone catheter was used. One-lumen catheters were used predominantly. Sedation of the patient was achieved with midazolam and fentanyl if patient was concuss and vigorous. Patients were adequately positioned for the procedure. The site of catheter insertion was cleaned initially with clorhexidin gluconat, with sterile saline and finally with clorhexidin in $70 \%$ isopropyl alcohol. Standard sterile technique - including the use of sterile gloves, gown, mask and cap - was used in all cases. The place of insertion was covered with a sterile covering. Catheters were inserted percutaneously following the Seldinger technique $(6,7)$. The preferred site for primary attempts was chosen according to the clinical condition of the patient. After the catheter was inserted, blood flow was checked and the lumen was flushed with normal saline. Catheters were sutured and covered with a transparent dressing. The catheters were maintained by either continuous infusion of heparin (1 unit/ $\mathrm{ml}$ ) or by heparin flushes of $10 \mathrm{units} / \mathrm{ml}$. Within two hours of CVC insertion, chest $X$-rays with contrast were obtained to confirm the tip was positioned above the pericardium, and to identify potential complications $(8,15)$. Two to three hours following catheter insertion, a patient's electrocardiogram, heart rate and oxygen saturation were monitored. Catheter blood flow and insertion site were checked and maintained daily.
Patients were carefully monitored for signs of catheter occlusion and catheter-related bloodstream infections (CRBI).

Isolation of the same microorganism from the catheter lumen and from the blood drawn from a peripheral vein, with accompanying clinical symptoms of sepsis, was accepted as proof of a CRBI (16). Whenever CRBI was diagnosed, the catheter was removed, and appropriate antibiotics were initiated. The frequency of CRBI was ex-pressed by number of sepsis cases per 1000 days of catheter stay.

Catheter malposition was defined as placement that required repositioning before use. Catheter damage was defined as separation or cracking of catheter line components during use (14).

$\chi^{2}$ test, Kruskal Wallis and Mann-Whitney test were used to determine factors associated with complications. A probability value of 0.05 was accepted as significant.

\section{Table 1. Insertion of CVCs by age group}

\begin{tabular}{lll}
\hline Age group & Number of patients & $\begin{array}{l}\text { Number of inserted } \\
\text { CVCs (\%) }\end{array}$ \\
\hline Newborns (0-28 days) & 122 & $151(42.9)$ \\
\hline 1 to $\leq 12$ months & 59 & $65(18.5)$ \\
\hline 1 to $\leq 6$ years & 51 & $61(17.3)$ \\
\hline 6 to $\leq 12$ years & 28 & $30(8.5)$ \\
\hline 12 to $\leq 18$ years & 40 & $45(12.8)$ \\
\hline Total & 300 & $352(100)$ \\
\hline
\end{tabular}

Table 2. Indications for CVCs insertion

\begin{tabular}{ll}
\hline Indications & Number of inserted CVCs(\%) \\
\hline Invasive hemodynamic monitoring & $65(18,5)$ \\
\hline Dialysis & $4(1,1)$ \\
\hline Blood exchange & $9(2,6)$ \\
\hline I.v. therapy longer than 14 days & $100(28,4)$ \\
\hline Parenteral nutrition & $76(21,6)$ \\
\hline Lack of peripheral i.v. access & $36(10,2)$ \\
\hline Prematurity & $52(14,8)$ \\
\hline Others & $10(2,8)$ \\
\hline Total & $352(100)$ \\
\hline
\end{tabular}

\section{RESULTS}

During the study period 1300 patients aged from 0 to 18 years were admitted to the PICU in SUH. A total of 352 CVCs were inserted into 300 patients. There were 119 female and 181 male patients (39.7\% and $60.3 \%$ respectively). Newborns were the biggest age group that needed CVC insertion (151, 42.9\%) (table 1). The difference between the number of patients and number of inserted CVCs is caused by multiple insertions of CVCs in some patients: $43(12.2 \%)$ had two, 2 (0.6\%) had three and $1(0.3 \%)$ patient had 4 catheters inserted. In two patients, two catheters were inserted at the same time because of a need for dialysis and parenteral nutrition. The average catheter placement time was 12.88 days with a range between 1-144 days. The cumulative placement time of all inserted CVCs was 4532 days.

The left subclavian vein was the pre- 
ferred place for insertion of CVCs in our patients (101 catheters, 28.7\%) (picture $1)$. The high proposition of newborns in our study accounts for the large percentage of umbilical vein catheters used (89, 25.3\%). Two-lumen catheters were inserted in 25 patients while onelumen catheters were inserted in the other patients.

Among the indications for CVC inser-

\section{Table 3. Complications related to CVCs insertion and stay}

\begin{tabular}{ll}
\hline Complications related to CVCs & A total number $(\%)$ \\
\hline Occlusion & $15(4,3)$ \\
\hline Malposition & $19(5,4)$ \\
\hline CRBI & $14(4,0)$ \\
\hline Pneumothorax & $3(0,9)$ \\
\hline Dislodgment & $13(3,7)$ \\
\hline Catheter damage & $2(0,6)$ \\
\hline Total & $66(18,8)$ \\
\hline
\end{tabular}

Table 4. Catheter related-bloodstream infections (CRBI) of inserted CVCs

\begin{tabular}{ll}
\hline Organism & Total \\
\hline Staphylococcus aureus & 1 \\
\hline Coagulase-negative Staphylococcus & 3 \\
\hline Candida albicans & 1 \\
\hline Klebsiella pneumoniae & 2 \\
\hline Methicillin-sensitive Staphylococcus epidermidis & 1 \\
\hline Methicillin-resistant Staphylococcus epidermidis & 5 \\
\hline nonenteric Gram-negative rods & 1 \\
\hline Total & 14 \\
\hline
\end{tabular}

tion, the need for intravenous therapy longer than 14 days was the most frequent reason (table 2).

Out of total of 352 placed CVCs, 66 (18.8\%) had one of the complications related to CVC insertion (table 3). The most frequent complication was malposition of CVC occuring in 19 (5.4\%) patients, then occlusion occuring in 15 (4.3\%) patients. Dislodgment occurred in $13(3.7 \%)$ patients, but in 8 patients it happened after their relocation to the Department of Pediatrics.

The most serious, among all notified complications, was CRBI. No catheter became infected during the first 48 hours after insertion. CRBI developed in 14 (4.0\%) patients (table 3). There were 3.1 CRBI per 1000 catheter-days. In 5, out of a total of 14 cases, the isolated organism was methicillin-resistant Staphylococcus epidermidis (table 4).

A significantly higher number of CRBIs occurred in newborns than in others age groups $\left(\chi^{2}=4.20 ; P=0.040\right)$. Three times more cases of $\mathrm{CRBI}$ were recorded when CVCs were inserted for provision of parenteral nutrition $\left(\chi^{2}=11.35\right.$; $\mathrm{P}<0.001)$. CRBI occurred in 6 cases when the CVC was inserted into umbilical vein, in 2 cases when it was inserted into the left subclavian vein, in 5 cases when it was inserted into the right subclavian vein and in 1 case following

Table 5. Catheter related-bloodstream infections (CRBI) in relations with other CVCs complications

\begin{tabular}{|c|c|c|c|c|}
\hline & & \multicolumn{2}{|c|}{ Patients with verified complications (N) } & \multirow[t]{2}{*}{$P^{*}$} \\
\hline & & CRBI & Other complications & \\
\hline \multirow[t]{2}{*}{ Age } & Newborns & 9 & 14 & 0,040 \\
\hline & Others & 3 & 25 & \\
\hline \multirow[t]{2}{*}{ Gender } & Female & 4 & 14 & 0,166 \\
\hline & Male & 8 & 15 & \\
\hline \multicolumn{5}{|l|}{ Mechanical } \\
\hline \multirow[t]{2}{*}{ ventilation } & Yes & 11 & 29 & 0,382 \\
\hline & No & 1 & 10 & \\
\hline \multicolumn{5}{|l|}{ Indications for } \\
\hline \multirow[t]{2}{*}{ CVC insertion } & Parenteral nutrition & 9 & 7 & $<0,001$ \\
\hline & Other indications & 3 & 32 & \\
\hline
\end{tabular}

* $\chi^{2}$ test with Yates correction 
insertion into the right femoral vein. CRBI was not significantly associated with gender, catheter type or mechanical ventilation (table 5).

\section{DISCUSSION}

Most complications related to CVCs are minor, but some of them can be serious and can result in patient death $(1,7)$. Our complication rate is within the limits of published data. Furthermore, major complications in our patients were rare. The incidence of the most important complication, CRBI, varies from $5 \%$ to $26 \%$ in adults (15) and from $3 \%$ to $20 \%$ in children (7). When calculated in relation to the length of stay, the incidence of CRBIs in adults varies from 2.4 to 12 per 1000 catheter days $(23,27)$. The incidence is higher in newborns (4.9 episodes of CRBI per 1000 catheter days), than in older children (2.4 episodes of CRBI per 1000 days) $(19,20)$. The low incidence of CRBIs in our patients is probably related to the expertise of our staff members who maintain aseptic condition in all procedures involving both insertion and managing of CVCs. In accordance with published data, Coagulase-negative Staphylococcus and Methicillin-resistant Staphylococcus epidermidis were the most common isolates in our patients with CRBI (7). It was found that the duration of the catheter use was critical for the occurrence of infections $(7,20)$. When catheters are in place for extended periods, the catheter hub probably plays a major role in providing access for microorganism to the bloodstream by migrating endoluminally (20). A higher catheter infection rate was noted in CVCs inserted for parenteral nutrition. This high rate is associated not only with the high concentration of nutrients in total parenteral nutrition solutions, but also with the length of stay of catheters designed for parenteral nutrition (26). Likewise, the majority of CRBIs in our study occurred in patients who were receiving parenteral nutrition, and all our patients with CRBIs were newborns.

The use of multilumen catheters for parenteral nutrition is highly desirable because it provides multipurpose

\section{Picture 1. Place of CVCs insertion}

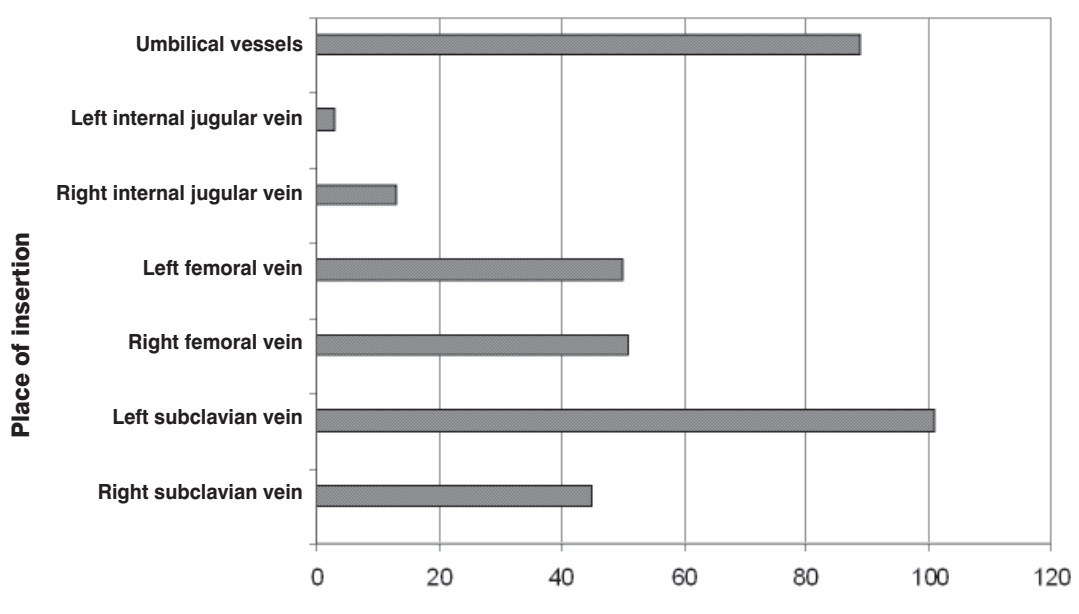

Number of insertion

access to central circulation and eliminates a need for additional intravenous access (19). However, the multiple lumen catheters bear the increased risk for $\mathrm{CRBI}(7,19,21,23)$. This statement is not unequivocal, and the results of our study support studies stating that multilumen catheters did not increase the risk for $\mathrm{CRBI}(27,28)$. It can be emphasized again that the adherence with the procedures for maintaining sterile conditions has a major influence on the occurrence of $\mathrm{CRBI}$.

All other complications that occurred in our study presented minor problems with no influence on morbidity. The most common complications during the procedure of insertion were malposition and pneumothorax. The malposition of CVCs required repositioning before catheter use, but was never associated with any further complications. Pneumothorax can be a serious complication, with the frequency of occurrence that varies between 0.01 and 6\% (7). In our study pneumothorax was only an incidental finding, that needed no intervention, and with a significantly low rate. Other serious complications reported in the literature include cardiac perforation, arteriovenous fistulas, nerve injuries (mostly brachial plexus injuries), cardiac tamponade, tension pneumothoraces, significant hemothoraces, delayed pneumothoraces, life-threatening arrhythmias, thoracic duct injuries and death $(1,24)$. None of our patients had any of these serious complications. Thrombosis is reported to occur in 2 to $67 \%$ CVCs $(7,15,29)$. We didn't notice any clinically apparent thromboses in our patients. However, most thromboses due to CVCs are asymptomatic (7, $25,26)$. Therefore, ultrasound follow-up, that would reveal asymptomatic thrombosis, should be performed regularly $(25,26,30)$. Occlusion of the CVCs was one of the most frequent complications in our study, but again within the expected range of $0 \%-7 \%(17,22)$. When occlusion occurred, it was tried to be relieved by flush with urokinase, and when urokinase failed we inserted a new CVC in the other place.

Published data on long-term central venous access can be compared only with great difficulties, due to considerable variations in study designs, patient populations, access routes and insertion techniques. The rates of infections and other complications in our study are in accordance with the results obtained from the pertinent literature. Therefore, we can conclude that percutaneous central venous catheterization can be recommended as a safe and efficient procedure with minimal complications in pediatric patients. However, the emphasis should be on strict adherence to existing guidelines when CVCs are inserted, and during subsequent care for CVCs (31). 


\section{REFERENCES}

1. Johnson EM, Saltzman DA, Suh G, Dahms RA, Leonard AS. Complications and risks of central venous catheter placement in children. Surgery 1998;124:911-6.

2. Jacobs BR. Central venous catheter occlusion and thrombosis. Crit Care Clin 2003:19:489-514.

3. Polderman KH, Girbes AJ. Central venous catheter use. Part 1: mechanical complications. Intensive Care Med 2002;28:1-17.

4. Asch MR. Venous acces: options, approaches and issues. Can Assoc Radiol J 2001;52:153-64.

5. Veenstra DL, Saint S, Sullivan SD. Cost-effectiveness of antiseptic-impregnated central venous catheters for the prevention of catheterrelated bloodstream infection. JAMA 1999; 282:554-60.

6. Sovinz P, Urban C, Lackner H et al. Tunneled femoral central venous catheters in children with cancer. Pediatrics 2001;107:104-9.

7. Çitak A, Karaböcüoğlu M, Üçsel R, Uzel N. Central venous catheters in pediatric patients - subclavian venous approach as the first choice. Pediatr Int 2002;44:83-6.

8. Gauderer MW. Vascular access techniques and devices in the pediatric patient. Surg Clin North Am 1992;72:1267-84.

9. Stovroff M, Teague WG. Intravenous acces in infants and children. Pediatr Clin North Am 1998;45:1373-93.

10. Wardle SP, Kelsall AW, Yoxall CW, Subhedar NV. Percutaneous femoral arterial and venous catheterisation during neonatal intensive care. Arch Dis Child Fetal Neonatal ED 2001;85:F119-22.

11. Serrao PR, Jean-Louis J, Godoy J, et al. Inferior vena cava catheterization in the neonate by the percutaneous femoral vein method. J Pernatol 1996;16:129-32.

12. Racadio JM et al. Pediatric peripherally inserted central catheters: complication rates related to catheter tip location. Pediatrics 2001;107:E28.

13. Venkataraman ST, Thompson AE, Orr RA. Femoral vascular catheterization in critically ill infants and children. Clin Pediatr 1997;36:311-9.

14. Stenzel JP, et al. Percutaneous femoral venous catheterizations: a prospective study of complications. J Pediatr 1989;114:411-5.

15. McGee DC, Gould MK. Preventing complications of central venous catheterization. N Engl J Med 2003;348:1123-33.

16. Benjamin DK Jr et al. Bacteriemia, central catheters, and neonates: when to pull the line. Pediatrics 2001;107:1272-6.

17. Thiagarajan RR, Ramamoorthy C, Gettmann T, Bratton SL. Survey of the use of peripherally inserted central venous catheters in children. Pediatrics 1997;99:E4.

18. O'Grady NP, Alexander M, Dellinger EP et al. Guidelines for the prevention of intravascular catheter-related infections. The Hospital Infection Control Practices Advisory Committee, Center for Disease Control and Prevention, u.s. Pediatrics 2002;110:E51.

19. Mahieu LM, De Dooy JJ, Lenaerts AE, leven MM, De Muynck AO. Catheter manipulations and the risk of catheter-associated bloodstream infection in neonatal intensive care unit patients. J Hosp Infect 2001;48:20-6.

20. Salzman MB, Rubin LG. Intravenous catheter-related infections. Adv Pediatr Infect Dis 1995;10:337-68.

21. Yeung C, May J, Hughes R. Infection rate for single lumen v triple lumen subclavian catheters. Infect Control Hosp Epidemiol 1988;9:154-8.

22. Soong WJ, Jeng MJ, Hwang B. The evaluation of percutaneous central venous catheters - a convenient technique in pediatric patients. Intensive Care Med 1995;21:759-65.

23. Menon G. Neonatal long lines. Arch Dis Child Fetal Neonatal Ed 2003;88:F260-2.

24. Darling JC, Newell SJ, Dear PRF. Placement of neonatal central venous catheter tips in the right atrium: a practice to be avoided? Arch Dis Child Fetal Neonatal Ed 2001;85:F146.

25. Krafte-Jacobs B, Sivit CJ, Mejia R, Pollack MM. Catheter-related thrombosis in critically ill children: Comparison of catheters with and without heparin bonding. J Pediatr 1995;126:50-4.

26. Kim JH, Lee YS, Kim SH, Lee SK, Lim MK, Kim HS. Does umbilical vein catheterisation lead to portal venous thrombosis? Prospective US evaluation in 100 neonates. Radiology 2001;219:645-50.

27. Savage AP, Picard M, Hopkins CC, Malt RA. Complications and survival of multilumen central venous catheters used for total parenteral nutrition. Br J Surg 1993;80:1287-90.

28. Johnson BH, Rypins EB. Single-lumen vs double-lumen catheters for total parenteral nutrition. A randomized, prospective trial. Arch Surg 1990;125:990-2.

29. Shah P, Shah V. Continuous heparin infusion to prevent thrombosis and catheter occlusion in neonates with peripherally placed percutaneous central venous catheters. Cochrane Database Syst Rev 2005;3: CD002772.

30. Crain MR, Horton MG, Mewissen MW. Fibrin sheaths complicating central venous catheters. AJR Am J Roentgenol 1998;171:341-6.

31. Koletzko B, Goulet O, Hunt J, Krohn K, Shamir R; Parenteral Nutrition Guidelines Working Group; European Society for Clinical Nutrition and Metabolism; European Society of Paediatric Gastroenterology, Hepatology and Nutrition (ESPGHAN); European Society of Paediatric Research (ESPR).. Guidelines on Pediatric Parenteral Nutrition of the European Society of Pediatric Gastroenterology, Hepatology and Nutrition (ESPGHAN) and the European Society for Clinical Nutrition and Metabolism (ESPEN), Supported by the European Society of Pediatric Research (ESPR). J Pediatr Gastroenterol Nutr 2005; 41 Suppl 2:S1-S87. 